\title{
Traumatic Subdural Effusion Evolving into Chronic Subdural Hematoma
}

\author{
Seidu A. Richard, Mingcan Wu*, Dong Lin \\ Department of Neurosurgery, Jingzhou No. 1 People's Hospital, Clinical Medical College, Yangtze University, \\ Jingzhou, China \\ Email: wumingcan@yantzeu.edu.cn
}

Received 25 October 2014; revised 25 November 2014; accepted 25 December 2014

Copyright (C) 2015 by authors and Scientific Research Publishing Inc.

This work is licensed under the Creative Commons Attribution International License (CC BY). http://creativecommons.org/licenses/by/4.0/

(c) (i) Open Access

\section{Abstract}

Background: Chronic subdural hematoma (CSDH) is a common complication in head injuries. The objective of this study is to establish the evolution of traumatic subdural effusion (TSDE) into CSDH using clinical signs and symptoms as well as radiology. Our aim is to effectively manage such cases without postoperative recurrence (PR). Methodology: The study was a retrospective cohort carried out in the No. 1 People's Hospital of Jingzhou from August 2007 to November 2013. The hospital is affiliated to the Yangtze University. All the patients included in this study were involved in road traffic accidents and sustained various degree of head injury. Serial CT scans were done to establish the development TSDE and the evolution of the TSDE into CSDH and treatment options. Results: In all 159 patients developed TSDE and out of these 34 which constitute $21.38 \%$ had their TSDE evolving into CSDH. Most of the patients were elderly. Twelve patients were treated conservatively while the remaining patients were treated surgically by drilling and drainage of hematoma. All the patients survived with marked improvement in their sign and symptoms with no recurrence. Conclusion: TSDE is one of the etiological factors for the development of CSDH in the elderly although in most cases the etiology of CSDH is usual multifactory. It must be stated clearly that, the evolution of TSDE into CSDH is initially a hidden process and presents with nonspecific signs and symptoms which can easily be missed. CT scan is usually the initial radiology of choice in making diagnosis of TSDE but MRI could be used to make early diagnosis of the transgression of TSDE into CSDH, and hence early surgical intervention before the formation of a neomembrane could reduce $P R$ rate.

\section{Keywords}

Traumatic Subdural Effusion (TSDE), Chronic Subdural Hematoma (CSDH), Co-Morbid Conditions, Postoperative Recurrence (PR)

\footnotetext{
${ }^{*}$ Corresponding author.
} 


\section{Introduction}

Chronic subdural hematoma (CSDH) was first described by Virchow in 1857 who thought it was due to "pachymeningitis hemorrhagica interna” [1]-[3]. In 1894 Mayo first noted traumatic subdural hydroma and defined it as the accumulation of cerebrospinal fluid (CSF) in the subdural space because of rupture of the arachnoid after head injury [2] [4]. MacConnell who also noticed the same condition described it as traumatic subdural effusion (TSDE) no matter the cause of the accumulation of fluid in the subdural space [4]. Yamada et al. in 1979 were the first to propose the link between TSDE and CSDH although they could not explain the pathogenic process involving the two conditions [2] [5]. Up to date the pathogenesis of the evolution of TSDE into CSDH is still a matter of debate and no one has clearly defined it. Although they is still no clear distinction between TSDE and CSDH [2] [5]-[8], a neomembrane is almost always present in CSDH but TSDE often lacks membrane [9].

\section{Objectives}

The objectives of this study is to establish the evolution of TSDE into CSDH using clinical signs and symptoms as well as radiology. The main aim is effective manage CSDH using conservative approach and surgical technique of drilling and drainage of hematoma without PR.

\section{Methodology}

The study was a retrospective cohort carried out in the No. 1 People's Hospital of Jingzhou from August 2007 to November 2013. The hospital is affiliated to the Yangtze university. The annual admission in the neurosurgery unit is estimated to be about 1500 patients. Patients who were admitted during this period as a result of traumatic head injury were included in the study. CT scans were done in the first 24 hours after the accident and repeated every 72 hours to 10 days to identify patients that developed TSDE. Patients who developed TSDE were further followed weekly through serial CT scans to determine if their TSDE has evolved into CSDH. Patients demographic data (sex, age), clinical signs and symptoms, comorbid factors, and the CT scan finding above were documented.

The relatives of all the patients included in this study were informed appropriately since most of the patient were not in the right frame of mind and they all agreed to participate in the study. Patients relatives signed all agreement documents pertaining to their management before any procedures were done. The protocol for the research project was also approved by Yangtze University and the No. 1 People’s Hospital of Jingzhou before the study was undertaken. We did not record indeterminate results, missing data, and data outliers because all the patients included in the study agreed to participate and the attached seriousness to the study.

The mode of treatment was in two methods, conservatively and surgical. The surgical treatment involved drilling the skull and drainage of the hematoma.

\section{Surgical Technique}

Using the CT scans as a guard, the hair on the scalp were shaved and skin prepare under strict aseptic conditions. Incisions were made on the scalp, drilling and expansion of the hole on the bone with ronguer to about 1.5 $\times 1.5 \mathrm{~cm}$. The dura was cut across and clotted blood removed. Dura was suspended, cavity was well rinsed with normal saline and drained to make sure all clotted blood were removed. A drainage tube was placed into the cavity and sutures layered to close the scalp and hold the drainage tube so that it does not fall off. Patient was then nursed on a pillow for 2 days. The drainage tube was pulled out if blood had stop flowing and the sutures removed the next week. Follow up visits were scheduled with patients and review CT scans done to determine PR.

\section{Results}

In all 159 patients developed TSDE and out of these 34 which constitute $21.38 \%$ had their TSDE evolving into CSDH as shown in the Table 1 . We notice that the time frame for the effusion to accumulate ranges from 3 to 11 days with an average of $9.40 \pm 0.82$ days. However the time interval of the TSDE evolving into CSDH ranges from 4 to 18 weeks with average of $5.62 \pm 0.78$ weeks. 
Table 1. Distribution of cases who develop TSDE and the those who developed CSDH.

\begin{tabular}{cc}
\hline Pathology/disease & Number of cases \\
\hline Chronic subdural effusion & 159 \\
Chronic subdural hematoma & 34 \\
\hline
\end{tabular}

\subsection{Age and Sex}

Most of the patients where elderly with their ages ranging from 38 years to 78 years with a mean age of $56.8 \pm$ 10.28 years old. Males were 19 and females were 15 as shown in Table 2.

\subsection{Co-Morbid Conditions}

During CT-scan evaluation of the patients whose TSDE evolved into CSDH we also noticed that 10 of the patients have associated brain contusions (including contralateral and multiple injuries), 8 had acute subarachnoid hemorrhage and 6 of them had skull fractures. We are of the view that these associated co-morbid conditions has also contributed to the development of TSDE in 24 patients included in this study. The remaining 10 patient had spontaneous evolution of TSDE into CSDH. The brain contusions lead to edema and exudation of fluids into the subdural space hence the TSDE. The fractures also leads to tears in the dura resulting in leakage of CSF and bleeding of small AG veins into the subdural space hence the accumulation of the effusion. As shown in the Table 3 .

\subsection{Clinical Manifestations}

The mechanism of injury is mostly road traffic accidents (motor cycle or motor crash) which is usual due to acceleration and deceleration as well as fall from heights. patients usually present at open patients department (OPD) with bruises and wounds. We notice that the initial signs and symptoms of patients at presentation were Headache in twelve (12) cases, vomiting in five (5) cases, seven (7) cases of paralysis and altered consciousness, dementia six (6) cases, four (4) cases of psychiatric symptoms (Table 4).

\subsection{Imaging}

TSDE is seen on CT scans as a collection of fluid within the subdural that have similar imaging characteristic to the CSF [10] while CSDH is seen as a crescent sharped hypo-dense region in the cerebral convexity [11]-[13]. we noticed TSDE on the CT scans first 3 days after the traumatic head injury. Four cased were noticed between the periods of 4 to 7 days and 29 cases notice eight days later. However CSDH's were notice 4 to 18 weeks after the initial diagnosis of subdural effusion. Figures 1-5 are serial CT scan of one of the patients whose TSDE evolved into CSDH. The CT scans are arranged sequentially.

\subsection{Treatment}

Twelve (12) patients were treated conservatively while the remaining were treated surgically by drilling and drainage of hematoma. This simple surgical technique described above was the reason why we did not record PR. All the patients recovered with conventional, anti-inflammatory, homeostatic fluids. Clinical signs and symptoms like headaches, paralyses, and demential improved remarkably. Co-morbid conditions were also treated accordingly and all patients discharged home. CT scan done on scheduled reviews 6 months later show no PR of hematoma in all patients both surgically and conservatively treated. ventricular sizes returned to normalcy in all patients groups. All the patient were review again in a year interval and there were still no PR in all patients groups. As shown in Table 5.

\subsection{Postoperative Recurrence (PR)}

We did not record any PR in all the patient we managed in our study due to early surgical intervention before the maturation of the neomembrane and early expansion of the brain. Expansion of the brain closes the space created by the CSDH and hence occlusion of potential rebleeding vessels hence prevents rebleeding. 


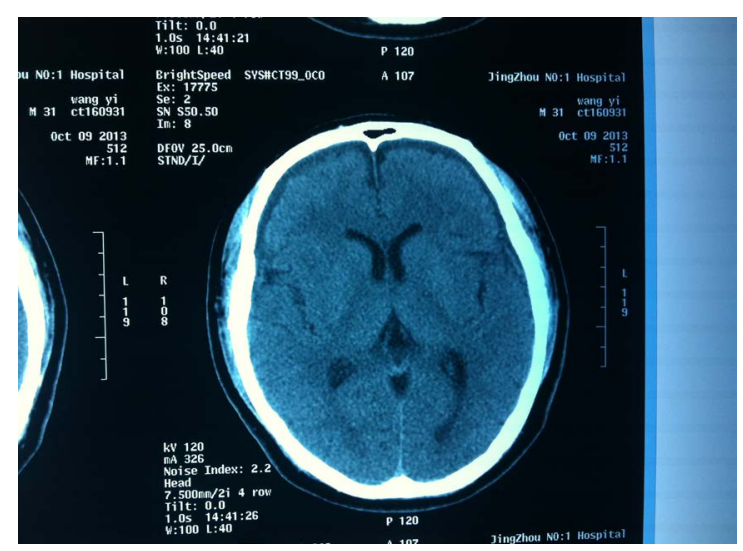

Figure 1. Three (3) days after traumatic Head injury, the patient develops TSDE which seen on the CT scan below as a collection of fluid within the subdural that have similar imaging characteristic to the cerebrospinal fluid (Oct. 9).

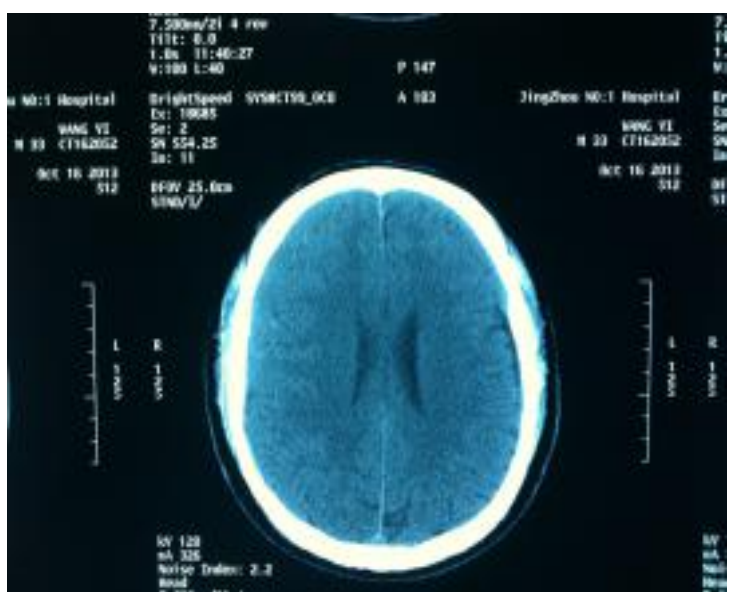

Figure 2. Ten (10) days after the traumatic head injury, the TSDE started changing appearance on the CT scan from CSF like appearance to light hypodense (Oct. 16).

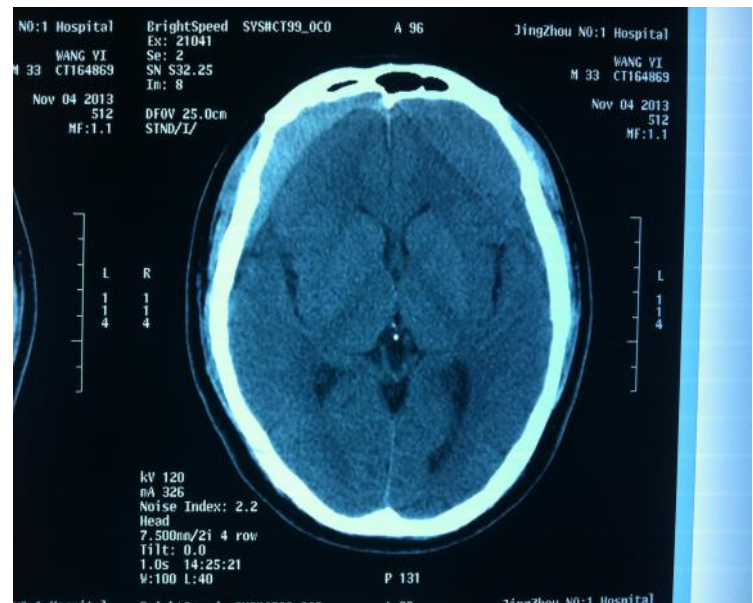

Figure 3. Seventeen (17) days after the traumatic head injury the TSDE had evolved into CSDH which seen on the CT scan as a crescent sharped hypodense region in the cerebral convexity (Oct. 23). 


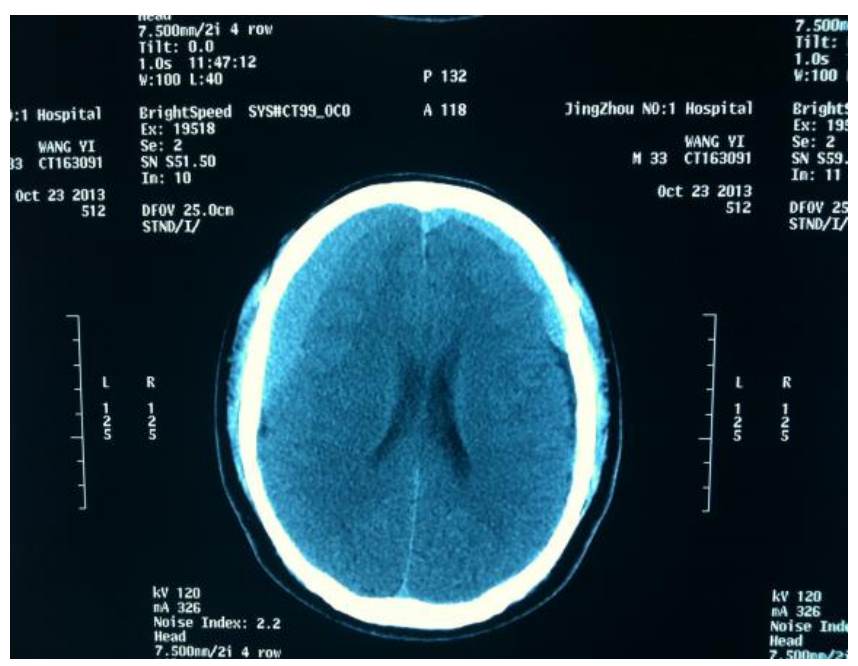

Figure 4. Twenty-nine (29) days after the head injury, the CSDH was increasing in size despite medical treatment (Nov. 4).

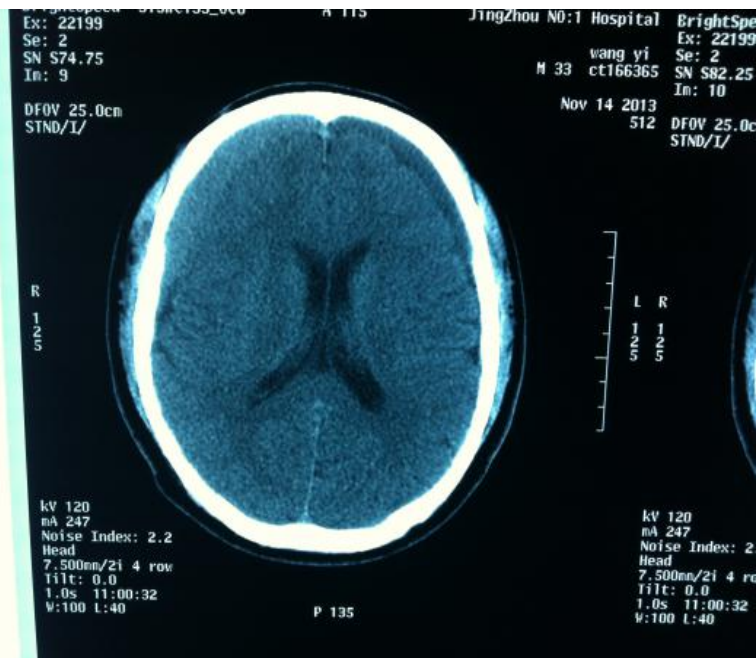

Figure 5. Thirty-nine (39) days after the traumatic Head injury, the CSDH was resolving gradually after surgical intervention (Nov. 14).

Table 2. Age and sex distribution of patients who develop CSDH.

\begin{tabular}{cc}
\hline Sex/age & Number of cases \\
Males & 19 \\
Females & 15 \\
Age distribution & $38-78$. Mean age $=56.8 \pm 10.24$ \\
\hline
\end{tabular}

Table 3. Co-morbid conditions associated with patients whose TSDE evolved into CSDH.

\begin{tabular}{cc}
\hline Co-morbid condition & Number of cases \\
\hline Brain contusions & 10 \\
Subarachnoid hemorrhage & 8 \\
Skull fracture & 6 \\
\hline
\end{tabular}


Table 4. Clinical signs and symptoms of patients whose TSDE evolved into CSDH.

\begin{tabular}{cc}
\hline Signs \& symptoms & Number of cases \\
\hline Headaches & 12 \\
Vomiting & 5 \\
Paralyses \& altered consciousness & 7 \\
Dementia & 6 \\
Psychiatric symptoms & 4 \\
\hline
\end{tabular}

Table 5. Treatment options for patients who develop CSDH, outcomes and recurrence.

\begin{tabular}{cccc}
\hline Treatment option & Number of cases & Outcome & Recurrence \\
\hline Conservative & 12 & All patients survived and function improved & No recurrence \\
Surgical & 33 & All patients survived and function improved & No recurrence \\
\hline
\end{tabular}

\section{Discussion}

\subsection{Pathophysiology}

TSDE is an accumulation of cerebrospinal fluid in the subdural space and is frequently associated with a modified CSF composition [14]. Most TSDEs are asymptomatic. 76.62\% of the patients who developed TSDE resolved with conservative treatment alone, which means that TSDE usually disappear when brain expansion or absorption exceeds effusion [15]. Two theories have been proposed to explain the development of CSDHs: the theory of osmotic gradients and the theory of recurrent hemorrhage from the hematoma capsule associated with the hyper-fibrinolysis. The second hypothesis is more widely accepted [15] [16].

Most patients were elderly (mean age of $56.8 \pm 10.24$ ), demented or chronic alcoholics, and brain atrophy is the most important predisposing factor. Brain atrophy in the elderly creates a potential space in which fluid can easily collect. The subdural space is not present in normal healthy people, but trivial trauma can separate the dura-arachnoid interface, which is the so-called dura border cell layer [14] [17]. When sufficient potential subdural space is present owing to age and cortical atrophy, absorption of the TSDE will generally be delayed. The atrophic brain often fails to reexpand rapidly, leading to the persistence of TSDE. Low intracranial pressure or atrophy promotes the development of CSDH [15] [18]. The cycle of persistent accumulation of effusion in the subarachnoid, rebleeding from torn small AG veins, coagulation and fibrinolysis contributes to the development and maintenance of CSDH [19] [20]. Furthermore elderly patients still has functional hypercoagulative and hyperfibrinolytic activities which are enhanced after slight head injury, resulting in CSDH [15]. Some researches have found specific and sensitive molecular markers for coagulation or fibrinolytic systems that are related to CSDH [20]. They have shown that fibrinogen is an indicator of rebleeding; thrombin is a sensitive marker of coagulation; and tissue type plasminogen activator (tPA) and fibrin degradation product (FDP) (a fibrin monomer and D-dimer) are indicators of fibrinolytic activity [15]. Delayed resorption of the TSDE results in hemorrhage into the subdural fluid, which is due to the tearing of bridging veins or bleeding from the neomembrane [14] [18] [21]. Bleeding that is due to the tearing of bridging veins occurs because the veins are already elongated. A neomembrane will be formed if the TSDE with a bleeding component persists [15]. However, a high concentration of fibrinogen in TSDE can be evidence of continuous rebleeding, as fibrinogen is introduced into the cavity of a hematoma only by repeated bleeding and should disappear immediately through the action of thrombin [19] [20].

Thrombin generation occurs in the subdural space of patients with TSDE and accelerates in the subsequent CSDH [19] [20]. Thrombin is generated after bleeding during hemostasis, and provokes the proliferation of fibroblasts, chemotaxis of inflammatory cells and angiogenesis in the dura mater to form the outer membrane, which resembles the granulation tissue that is observed during tissue repair [22]. Bleeding in the TSDE induces the migration or proliferation of inflammatory cells that are derived from the dural border cells, resulting in a layer of fibroblasts along the dura, which develops into the outer membrane of the hematoma [23]-[26]. Capillaries will develop with time once a neomembrane is formed. Hasegawa et al. showed that there are numerous 
vessels in the subdural neomembrane in TSDE, and many fenestrations and pinocytotic vesicles exist in the vessel wall [27]. The mechanism of outer membrane formation in CSDH, especially the angiogenesis of immature capillaries, is not well understood. However, immature capillaries in the outer membrane can produce tPA [28]. The outer membrane contains a large amount of tPA, so plasminogen can be consumed in the CSDH through the diffusion of soluble tPA from the outer membrane [19]. tPA causes local hyperfibrinolytic activity and bleeding. Hyperfibrinolysis that is caused by increased tPA may interfere with hemostasis and may induce the enlargement of CSDH. Weir and Gordon found high levels of tPA and FDP in the vascular outer membrane in 25 cases of CSDH [29] which suggests high fibrinolytic activity and potential further bleeding. The fibrinolytic activity of the fibrin monomer and D-dimer is used in the diagnosis of disseminated intravascular coagulation [30].

Some scholars disagree that the transition of TSDE into CSDH but rather acute blood components that causes CSDH. Acute subdural hematoma usually results from the tearing of bridge veins or cortical vessels, or from cortical laceration after trauma; it may be produced from a previous drainage operation for Subdural effusion or CSDH. The acute blood component after the initial head injury may be another cause of CSDH development; however, this is not an etiologic factor of primary importance.

\subsection{Radiology}

It is not easy to distinguish an acute or subacute subdural effusion with a lucent appearance from a CSDH with a hypodense one [9]. Most CSDH occur over the convexity of the cerebral hemisphere in the region of the frontal and parietal lobes [10] [31]. It is in this type of lesion that the effacement sign is commonly seen. The effacement sign is the result of the obliteration of the normal cerebrospinal fluid pathways between the cerebral gyri by a subdural collection with a density absorption coefficient that does not differ significantly from that of the underlying brain substance. It may be simulated by asymmetry of cortical sulci or appearance of unilateral effacement which can occur in unilateral cortical atrophy. When the radiological diagnosis CSDH becomes difficult two findings in the CT scan should alert the radiologist and neurosurgeon to this possibility: 1) a mass effect with shift of midline structures and/or unilateral compression of the ventricular system in the absence of abnormal areas of diminished or increased density within the brain to explain the abnormality; on 2) unilateral effacement of cortical sulci over the convexity of the brain.

\subsection{Treatment}

\subsubsection{Surgical Intervention}

The decision to evacuate a CSDH is influenced both by the radiographic appearance of the lesion as well as by the patient's neurological exam. An asymptomatic patient with a small CSDH is often best observed in a carefully monitored setting. The spontaneous resolution of CSDH of significant thickness has been reported in a small number of case series [32] [33]. It is generally accepted that in the presence of focal symptoms and/or significant changes in neurologic status, patients should undergo immediate operative evacuation. Multiple standard surgical techniques exist for the evacuation of CSDH, including twist drill craniostomy (TDC), burr-hole craniostomy (BHC), and craniotomy. In general, TDC produce the smallest openings of the skull $(<10 \mathrm{~mm})$, while BHC carried out using a high-speed drill enable larger openings ( $<30 \mathrm{~mm}$ in diameter). Removal of a substantial piece of bone $(>30 \mathrm{~mm})$ that is replaced and fixed to the skull defect following evacuation constitutes a craniotomy [34].

\subsubsection{Craniotomy}

Prior to modern imaging techniques, evacuation of a CSDH was accomplished primarily via craniotomy. This technique exposes the largest portion of the brain and thus provides the surgeon with the most expansive operative exposure. However, craniotomy is best performed under general anesthesia and is the most invasive of the options for treatment of CSDH, encompassing the greatest operative time as well as the greatest volume of blood loss. Despite the increased risks, craniotomy remains the best option for evacuation of organized, calcified, or CSDH with numerous thick membranes [35].

\subsubsection{Burr-Hole Craniostomy (BHC)}

BHC is the surgical treatment most frequently employed for CSDH [3] [36]. There are a number of variations of 
this technique. Some surgeons prefer a single burr-hole, whereas others use two [37], and there has not been conclusive evidence to definitively support either approach. The use of closed-system drainage after BHC has also been suggested to decrease the PR rate [38]. Although a recent survey suggested that many neurosurgeons preferred not to place a drain following burr-hole drainage of a CSDH [39]. Other surgeons have suggested subperiosteal (subgaleal) drainage catheters as an alternative to subdural catheters [40] [41].

\subsubsection{Twist-Drill Craniostomy (TDC)}

By comparison, TDC can be performed either at the bedside under local anesthesia or in the operating room using either local or general anesthesia. As TDC can be performed at the bedside, it is an attractive option for those elderly patients with multiple medical co-morbidities who are poor surgical candidates. However, TDC drainage is most effective in cases of CSDH in which the blood is almost completely liquefied, and there is a theoretical increased risk of contamination when performed at the bedside. A closed system Jackson-Pratt bulb drainage system is often placed at the time of surgery to allow for continuous drainage, which is thought to promote postoperative brain expansion, particularly in elderly patients with prominent brain atrophy [42].

\subsubsection{Adjunctive Techniques}

A number of additional adjunct techniques of CSDH drainage have been reported in the literature, and a review of these techniques is informative for the practicing neurosurgeon. Takeda et al. reported an interesting method for evacuation of chronic subdural Hematoma without the use of irrigation or drainage. The authors then injected 10 cc of oxygen into the hematoma cavity and aspirated an equal volume with a syringe. The patient's head was subsequently rotated from lateral to supine position according to the volume of hematoma. The authors were successful in evacuating hematoma in all of their patients, with satisfactory neurological recovery in 70 patients [43].

A variety of alternative techniques have also been promulgated in the setting of PR of hematoma. For example, a number of groups have reported on the efficacy of middle meningeal artery embolization in the treatment of refractory CSDH [44]-[47]. These series have all demonstrated angiography revealing abnormal vascular stains thought to represent formation of Neo-capillaries in the subdural membranes. In these several reports, no further enlargements or PR of the CSDH were observed following embolization of these vessels. An additional adjunctive technique proposed in the treatment of PR of CSDH is implantation of an ommaya reservoir, which permits repeated punctures and aspiration of subdural fluid. In an early prospective study by Laumer et al. [48] [49].

\section{Postoperative Recurrence (PR)}

Stanisic et al. are of the view that initial surgery for CSDH performed less than 60 days after head trauma tended to correlate to a high PR rate of $25.6 \%$ [50]. Nakaguchi et al. are of the view that limited organization of the younger hematoma (immature fibrosis of the neomembranes or trabeculae) may lead to an increased PR rate [25]. Choudhury who used two bole-holes craniotomy approach for 44 patients with CSDH and followed them from six to ten years with CT scan showed total disappearance of CSDH [37].

It has been shown that the pathophysiology of CSDH development is complex. It consists of a sequence of events which includes local inflammation, release of pro-inflammatory factors, angiogenesis, increased vasopermeability, bleeding, and hypercoagulative and hyperfibrinolytic activities. This leads to a self-enhancing vicious circle facilitating rebleeding and enlargement of the CSDH. Some reports discuss the variation of rebleeding tendency in different hematoma stages [25] [28]. During the initial stage of hematoma development (homogeneous type on CT scans), the rebleeding tendency is moderate because the balance between coagulative and fibrinolytic activities is maintained. In the two next chronological stages (laminar and separated types) the hyperfibrinolytic activity and tendency to rebleed from the neomembrane is high, but in the following stage (trabecular type) the risk of bleeding from the hematoma capsule is low because the neomembrane has a large fibrous component. This rebleeding tendency corresponds well with risk of recurrence. Thus, high rebleeding tendency in laminar and separated hematomas is associated with a high risk of PR and the low rebleeding tendency in homogeneous and trabecular hematomas is associated with a low risk of PR. Additionally, a high concentration of inflammatory cytokines in a separated hematoma correlated to high PR rate, whereas a low concentration in the trabecular hematoma correlated to low PR [51].

It has been stated that any factor leading to a prolonged postoperative widening of the hematoma cavity (brain 
atrophy, residual hematoma, massive subdural air collection, excessive fluid drainage through subdurally placed drains) may cause an impaired adhesion between the inner and outer neomembranes and thus facilitate PR [16] [52] [53].

\section{Conclusion}

TSDE is one of the etiological factors for the development of CSDH but in most cases the etiology of CSDE is multifactorial. Elderly patients who sustain traumatic head injury are at the highest risk of developing TDSE and subsequent evolution into CSDH. The diagnosis of TSDE and CSDH mostly relies on sign and symptoms as well as radiology. It must be stated clearly that, the evolution of TSDE into CSDH is initially a hidden process and presents with nonspecific signs and symptoms which can easily be missed. CT scan is usually the initial radiology of choice in making diagnosis of TSDE but MRI could be used to make early diagnosis of the transgression of TSDE into CSDH, and hence early surgical intervention before the formation of a neomembrane could reduce PR rate. Although there is a wide range of treatment options for the management of CSDH, as discussed above, the choice of treatment method should depend on the neurosurgeon. PR rate has been described by almost all the researches but we do not record any PR in all our patients we manage in our facility. This could be due to early surgical intervention and short follow up period of our patients. Our research findings as well as previous researches indicate that, one of the etiological factors for CSDH is TSDE. We did not have any major limitations during our study.

\section{Conflict of Interest Statement}

All authors certify that they have NO affiliations with or involvement in any organization or entity with any financial interest (such as honoraria; educational grants; participation in speakers' bureaus; membership, employment, consultancies, stock ownership, or other equity interest; and expert testimony or patent-licensing arrangements), or non-financial interest (such as personal or professional relationships, affiliations, knowledge or beliefs) in the subject matter or materials discussed in this manuscript.

\section{References}

[1] Virchow, R. (1857) Das Hamatom der Dura Mater. Verhandlungen der Physische-Medizinische Gesellschaft Wiirzburg, 7, 134-142.

[2] Ohno, K., Suzuki, R., Masaoka, H., Matsushima, Y., Inaba, Y. and Monma, S. (1987) Chronic Subdural Hematoma Preceded by Persistent Traumatic Subdural Fluid Collection. Journal of Neurology Neurosurgery and Psychiatry, 50, 1694-1697. http://dx.doi.org/10.1136/jnnp.50.12.1694

[3] Cenic, A., Bhandari, M. and Reddy, K. (2005) Management of Chronic Subdural Hematoma: A National Survey and Literature Review. Canadian Journal of Neurological Sciences, 32, 501-506.

[4] Li, Y.G., Gong, J., Li, F., Wang, H.W., Zhu, S.G. and Wu, C.Y. (2009) Traumatic Subdural Hydroma: Clinical Characteristics and Classification. Injury-International Journal of the Care of the Injured, 40, 968-972. http://dx.doi.org/10.1016/j.injury.2009.01.006

[5] Yamada, H., Kageyama, N., Nakajima, M. and Nakamura, S. (1979) Acute Posttraumatic Subdural Hematoma in Infancy: Special Reference to the Mechanism of Collection of Subdural Fluid. No Shinkei Geka, 7, 55-62.

[6] Takahashi, Y., Sato, H., Inoue, Y., Takeda, S. and Ohkawara, S. (1981) CT Findings and the Evaluation of Chronic Subdural Hematoma. Neurologia Medico-Chirurgica, 21, 485-490. http://dx.doi.org/10.2176/nmc.21.485

[7] Takahashi, Y., Mikami, J., Sato, H., Takeda, S., Matsuoka, T., Ito, K., Ueda, M. and Ohkawara, S. (1982) Analysis of Chronic Subdural Hematoma Based on CT (Part 2)—Symptoms and CT Findings. Neurologia Medico-Chirurgica, 22, 395-401. http://dx.doi.org/10.2176/nmc.22.395

[8] Yamada, H., Watanabe, T., Murata, S., Shibui, S., Nihei, H., Kohno, T. and Itoh, T. (1980) Developmental Process of Chronic Subdural Collections of Fluid Based on CT Scan Findings. Surgical Neurology, 13, 441-448.

[9] Stone, J.L., Lang, R.G.R., Sugar, O., Moody, R.A. (1981) Traumatic Subdural Hygroma. Neurosurgery, 8, 542-550. http://dx.doi.org/10.1227/00006123-198105000-00005

[10] Grossman, R.I. and Yousem, D.M. (2010) The Requisites Neuroradiology. 3rd Edition, Mosby, New York, 176-177.

[11] French, B.N. and Dublin, A.B. (1977) The Value of Computerized Tomography in the Management of 1000 Consecutive Head Injuries. Surgical Neurology, 7, 171-183. 
[12] Keiji, M. (1993) Chronic Subdural Hematoma May Be Preceded by Persistent Traumatic Subdural Effusion. Neurologia Medico-Chirurgica, 33, 691-696. http://dx.doi.org/10.2176/nmc.33.691

[13] Lankan, W., Meese, W. and Kazner, E. (1976) CT Findings in Closed Head Injuries with Special Reference to Contusion. In: Lanksch, W. and Kazner, E., Eds., Cranial Computerized Tomography, Springer-Verlag, New York, 318-320.

[14] Lee, K.S. (1998) The Pathogenesis and Clinical Significance of Traumatic Subdural Hygroma. Brain Injury, 12, 595603. http://dx.doi.org/10.1080/026990598122359

[15] Seong-Hyun, P., Sun-Ho, L., Jaechan, P., Jeong-Hyun, H., Sung-Kyoo, H. and In-Suk, H. (2008) Chronic Subdural Hematoma Preceded by Traumatic Subdural Hygroma. Journal of Clinical Neuroscience, 15, 868-872. http://dx.doi.org/10.1016/j.jocn.2007.08.003

[16] Markwalder, T.M., Steinsiepe, K.F., Rohner, M., Rohner, M., Reichenbach, W. and Markwalder, H. (1981) The Course of Chronic Subdural Haematomas after Burr-Hole Craniostomy and Closed-System Drainage. Journal of Neurosurgery, 55, 390-396. http://dx.doi.org/10.3171/jns.1981.55.3.0390

[17] Liu, Y., Zhu, T. and Jiang, Y. (2002) Chronic Traumatic Subdural Hematoma Fluid Evolution. Chinese Journal of Trauma, 40, 360-362.

[18] Apfelbaum, R.I., Guthkelch, A.N. and Shulman, K. (1974) Experimental Production of Subdural Hematomas. Journal of Neurosurgery, 40, 336-346. http://dx.doi.org/10.3171/jns.1974.40.3.0336

[19] Ito, H., Komai, T. and Yamamoto, S. (1978) Fibrinolytic Enzyme in the Lining Walls of Chronic Subdural Hematoma. Journal of Neurosurgery, 48, 197-200. http://dx.doi.org/10.3171/jns.1978.48.2.0197

[20] Ito, H., Saito, K., Yamamoto, S. and Hasegawa, T. (1988) Tissue-Type Plasminogen Activator in the Chronic Subdural Hematoma. Surgical Neurology, 30, 175-179. http://dx.doi.org/10.1016/0090-3019(88)90269-8

[21] Watanabe, S., Shimada, H. and Ishii, S. (1972) Production of Clinical Form of Chronic Subdural Hematoma in Experimental Animals. Journal of Neurosurgery, 37, 552-561. http://dx.doi.org/10.3171/jns.1972.37.5.0552

[22] Wakefield, T.W., Greenfield, L.J., Rolfe, M.W., DeLucia, A., Strieter, R.M., Abrams, G.D., Kunkel, S.L., Esmon, C.T., Wrobleski, S.K. and Kadell, A.M. (1993) Inflammatory and Procoagulant Mediator Interactions in an Experimental Baboon Model of Venous Thrombosis. Thrombosis and Haemostasis, 69, 164-172.

[23] Friede, R.L. and Schachenmayer, W. (1978) The Origin of Subdural Neomembranes. II. Fine Structures of Neomembranes. American Journal of Pathology, 92, 69-84.

[24] Kawano, N., Endo, M., Saito, M. and Yada, K. (1988) Origin of the Capsule of Chronic Subdural Hematoma-An Electron Microscopic Study. No Shinkei Geka, 16, 747-752.

[25] Nakaguchi, H., Tanishima, T. and Yoshimasu, N. (2001) Factors in the Natural History of Chronic Subdural Hematomas That Influence Their Postoperative Recurrence. Journal of Neurosurgery, 95, 256-262. http://dx.doi.org/10.3171/jns.2001.95.2.0256

[26] Schachenmayr, W. and Friede, R.L. (1978) The Origin of Subdural Neomembranes. I. Fine Structure of the DuraArachnoid Interface in Man. American Journal of Pathology, 92, 53-68.

[27] Hasegawa, M., Yamashima, T., Yamashita, J., Suzuki, M. and Shimada, S. (1992) Traumatic Subdural Hygroma: Pathology and Meningeal Enhancement on Magnetic Resonance Imaging. Neurosurgery, 31, 580-585. http://dx.doi.org/10.1227/00006123-199209000-00024

[28] Nomura, S., Kashiwagi, S., Fujisawa, H., Ito, H. and Nakamura, K. (1994) Characterization of Local Hyperfibrinolysis in Chronic Subdural Hematomas by SDS-PAGE and Immunoblot. Journal of Neurosurgery, 81, 910-913. http://dx.doi.org/10.3171/jns.1994.81.6.0910

[29] Weir, B. and Gordon, P. (1983) Factors Affecting Coagulation: Fibrinolysis in Chronic Subdural Fluid Collections. Journal of Neurosurgery, 58, 242-245. http://dx.doi.org/10.3171/jns.1983.58.2.0242

[30] Elms, M.J., Bunce, I.H., Bundesen, P.G., Masci, P.P., Rylatt, D.B., Whitaker, A.N. and Webber, A.J. (1986) Rapid Detection of Crosslinked Fibrin Degradation Products in Plasma Using Monoclonal Antibody-Coated Latex Particles. American Journal of Clinical Pathology, 85, 360-364.

[31] Mernit, H.H. (1973) Textbook of Neurology. 5th Edition, Lea \& Febiger, Philadelphia.

[32] Goksu, E., Akyuz, M., Ucar, T. and Kazan, S. (2009) Spontaneous Resolution of a Large Chronic Subdural Hematoma: A Case Report and Review of the Literature. Turkish Journal of Trauma \& Emergency Surgery, 15, 95-98.

[33] Parlato, C., Guarracino, A. and Moraci, A. (2000) Spontaneous Resolution of Chronic Subdural Hematoma. Surgical Neurology, 53, 312-317. http://dx.doi.org/10.1016/S0090-3019(00)00200-7

[34] Weigel, R., Schmiedek, P. and Krauss, J.K. (2003) Outcome of Contemporary Surgery for Chronic Subdural Haematoma: Evidence Based Review. Journal of Neurology, Neurosurgery \& Psychiatry, 74, 937-943.

http://dx.doi.org/10.1136/jnnp.74.7.937 
[35] Imaizumi, S., Onuma, T., Kameyama, M. and Naganuma, H. (2001) Organized Chronic Subdural Hematoma Requiring Craniotomy_Five Case Reports. Neurologia Medico-Chirurgica, 41, 19-24. http://dx.doi.org/10.2176/nmc.41.19

[36] Rohde, V., Graf, G. and Hassler, W. (2002) Complications of Burr-Hole Craniostomy and Closed-System Drainage for Chronic Subdural Hematomas: A Retrospective Analysis of 376 Patients. Neurosurgical Review, 25, 89-94. http://dx.doi.org/10.1007/s101430100182

[37] Choudhury, A.R. (1994) Avoidable Factors That Contribute to Complications in the Surgical Treatment of Chronic Subdural Haematoma. Acta Neurochirurgica, 129, 15-19. http://dx.doi.org/10.1007/BF01400867

[38] Wakai, S., Hashimoto, K., Watanabe, N., Inoh, S., Ochiai, C. and Nagai, M. (1990) Efficacy of Closed-System Drainage in Treating Chronic Subdural Hematoma: A Prospective Comparative Study. Neurosurgery, 26, 771-773. http://dx.doi.org/10.1227/00006123-199005000-00006

[39] Santarius, T., Lawton, R., Kirkpatrick, P.J. and Hutchinson, P.J. (2008) The Management of Primary Chronic Subdural Haematoma: A Questionnaire Survey of Practice in the United Kingdom and the Republic of Ireland. British Journal of Neurosurgery, 22, 529-534. http://dx.doi.org/10.1080/02688690802195381

[40] Gazzeri, R., Galarza, M., Neroni, M., Canova, A., Refice, G.M. and Esposito, S. (2007) Continuous Subgaleal Suction Drainage for the Treatment of Chronic Subdural Haematoma. Acta Neurochirurgica, 149, 487-493. http://dx.doi.org/10.1007/s00701-007-1139-8

[41] Zumofen, D., Regli, L., Levivier, M. and Krayenbuhl, N. (2009) Chronic Subdural Hematomas Treated by Burr Hole Trepanation and a Subperiostal Drainage System. Neurosurgery, 64, 1116-1122. http://dx.doi.org/10.1227/01.NEU.0000345633.45961.BB

[42] Ducruet, A.F., Grobelny, B.T., Zacharia, B.E., Hickman, Z.L., DeRosa, P.L., Anderson, K., Sussman, E., Carpenter, A. and Connolly, E.S. (2012) The Surgical Management of Chronic Subdural Hematoma. Neurosurgical Review, 35, 155169. http://dx.doi.org/10.1007/s10143-011-0349-y

[43] Takeda, N., Sasaki, K., Oikawa, A., Aoki, N. and Hori, T. (2006) A New Simple Therapeutic Method for Chronic Subdural Hematoma without Irrigation and Drainage. Acta Neurochirurgica (Wien), 148, 541-546. http://dx.doi.org/10.1007/s00701-005-0689-x

[44] Ishihara, H., Ishihara, S., Kohyama, S., Yamane, F., Ogawa, M., Sats, O. and Matsutani, M. (2007) Experience in Endovascular Treatment of Recurrent Chronic Subdural Hematoma. Interventional Neuroradiology, 13, 141-144.

[45] Mandai, S., Sakurai, M. and Matsumoto, Y. (2000) Middle Meningeal Artery Embolization for Refractory Chronic Subdural Hematoma. Case Report. Journal of Neurosurgery, 93, 686-688. http://dx.doi.org/10.3171/jns.2000.93.4.0686

[46] Mitsuomi, K., Teruhiko, T., Michiaharu, N., Masaki, M., Shinjitsu, N., Emiko, H., Misak, K., Shingo, Y. and Hioshi, M. (2010) Efficacy of Middle Meningeal Artery Embolization in the Treatment of Refractory Chronic Subdural Hematoma. Surgical Neurology International, 35, 155-169.

[47] Takahashi, K., Muraoka, K., Sugiura, T., Maeda, Y., Mandai, S., Gohda, Y., Kawauchi, M. and Matsumoto, Y. (2002) Middle Meningeal Artery Embolization for Refractory Chronic Subdural Hematoma: 3 Case Reports. No Shinkei Geka, 30, 535-539.

[48] Laumer, R., Schramm, J. and Leykauf, K. (1989) Implantation of a Reservoir for Recurrent Subdural Hematoma Drainage. Neurosurgery, 25, 991-996. http://dx.doi.org/10.1227/00006123-198912000-00026

[49] Sato, M., Iwatsuki, K., Akiyama, C., Kumara, E. and Yoshimine, T. (2001) Implantation of a Reservoir for Refractory Chronic Subdural Hematoma. Neurosurgery, 48, 1297-1301.

[50] Stanisic, M., Lund-Johansen, M. and Mahesparan, R. (2005) Treatment of Chronic Subdural Hematoma by Burr-Hole Craniostomy in Adults: Influence of Some Factors on Postoperative Recurrence. Acta Neurochirurgica (Wien), 147, 1249-1257. http://dx.doi.org/10.1007/s00701-005-0616-1

[51] Frati, A., Salvati, M., Mainiero, F., Ippoliti, F., Rocchi, G., Raco, A., Caroli, E., Cantore, G. and Delfini, R. (2004) Inflammation Markers and Risk Factors for Recurrence in 35 Patients with a Posttraumatic Chronic Subdural Haematoma: A Prospective Study. Journal of Neurosurgery, 100, 24-32. http://dx.doi.org/10.3171/jns.2004.100.1.0024

[52] Markwalder, T.M. (1981) Chronic Subdural Hematomas: A Review. Journal of Neurosurgery, 54, 637-645. http://dx.doi.org/10.3171/jns.1981.54.5.0637

[53] Nakaguchi, H., Tanishima, T. and Yoshimasu, N. (2000) Relationship between Drainage Catheter Location and Postoperative Recurrence of Chronic Subdural Haematoma after Burr-Hole Irrigation and Closed-System Drainage. Journal of Neurosurgery, 93, 791-795. http://dx.doi.org/10.3171/jns.2000.93.5.0791 
Scientific Research Publishing (SCIRP) is one of the largest Open Access journal publishers. It is currently publishing more than 200 open access, online, peer-reviewed journals covering a wide range of academic disciplines. SCIRP serves the worldwide academic communities and contributes to the progress and application of science with its publication.

Other selected journals from SCIRP are listed as below. Submit your manuscript to us via either submit@scirp.org or Online Submission Portal.
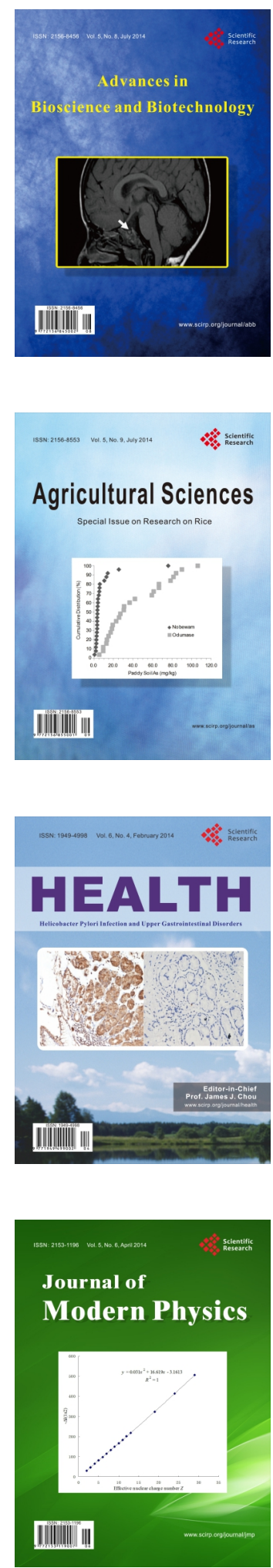
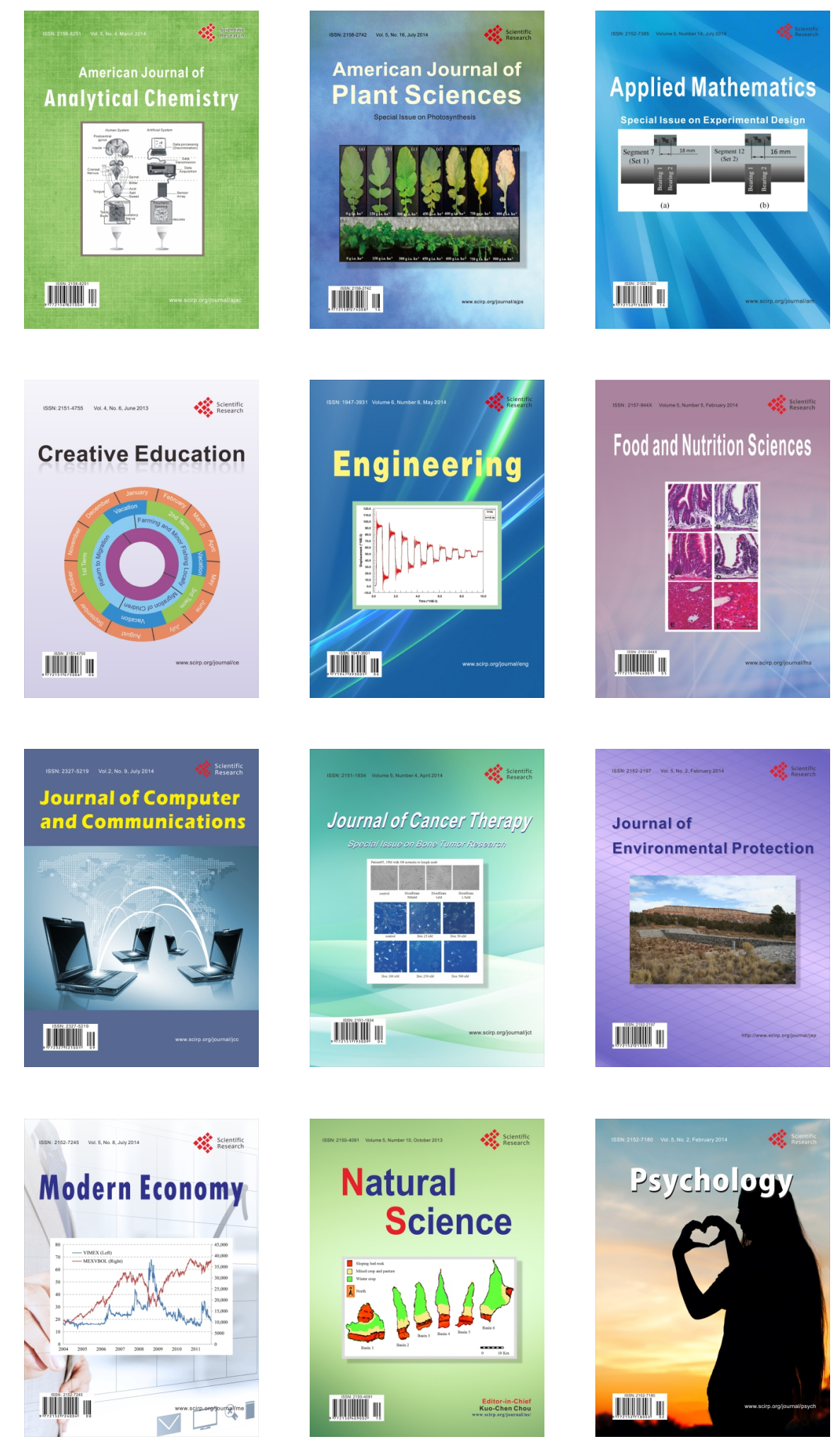